\title{
A Short Note on 'Responsibility' and 'Engagement'
}

\author{
Khairil Annuar Mohd Kamal* \\ Faculty of Economics and Business, \\ Universiti Malaysia Sarawak, \\ 94300 Kota Samarahan, \\ Sarawak, Malaysia. \\ mkkhairil@unimas.my
}

\begin{abstract}
In this paper I illustrate my simple thoughts on what I argue to be empty and vague concepts of 'responsibility' and 'engagement'. I argue that 'responsibility' and 'engagement' are aspirations of the hegemonic stakeholders that are imposed to the subaltern stakeholders. In other words the concepts of 'responsibility' and 'engagement' are nothing but tools for hegemonic stakeholders to exert power over the subaltern stakeholders.
\end{abstract}

Keywords: responsibility, stakeholder engagement, hegemonic stakeholder, subaltern stakeholder

\section{Introduction}

This short note is an appendix to my other working papers (particularly these papers: $\boldsymbol{A}$ Naïve Framework for Responsible Business Innovation, A Naive Framework of Stakeholder Engagement and A Methodology to Analyze Stakeholder Engagement: The Firm and a Subaltern Stakeholder and the more recent Responsible Innovation and an Informal Model of Stakeholder's Welfare and Purchasing Transaction and the Welfare of the Customer) with regards to two concepts relating to the wellbeing or welfare of the stakeholder. These concepts are 'responsibility' and 'engagement'. In this note I will begin with a brief discussion of my motivation and then I will write on what I think about the concepts of 'responsibility' and 'engagement' as aspirations of hegemonic stakeholders that are being directed forced to subaltern stakeholders.

\section{The Motivation}

The motivation of this note comes from my curiosity with regards to the fundamental or core ideas underlying the RESPONSIBILITY Project (which is funded by the European Union). This project in turn serves as the basis and core of another research project which is Sensitizing Stakeholder's Engagement in Promoting Responsible Business Innovation - this is the research project that underlies the papers which were mentioned in the introduction. What I am curious about and therefore interested are the terms responsibility and engagement. These terms are core in the RESPONSIBILITY Project and by that virtue these terms are core to my own research. In the first instance I have to say that I am skeptical of these two terms. In the first glance, these two terms sound mundane and ordinary. As such the meanings of these two terms should be well established, but that is too good to be true.

Indeed, if one considers the vast literature and references to find the meanings of these terms it would be difficult to find a consistent definition in terms actionable efforts that are needed to achieve or realize the states or situation that would be regarded as 'responsible' or being 'engaged' with

\footnotetext{
* Corresponding Author: Department of Business, Faculty of Economics and Business, Universiti Malaysia Sarawak, 94300 Kota Samarahan, Sarawak, Malaysia.
} 